\title{
Investigation on the Management Status of K-Pop Revenue Model and Finding Ways for Improvement
}

\author{
Sang Yeob Kim
}

\begin{abstract}
Korean Wave, the significant increase in the popularity of South Korean entertainment and culture, is sweeping across the whole world. One of its biggest contributors is music, often designated as K-Pop, and when this factor is studied critically, the art world can realize that therein lie problems with its revenue model and propose possible solutions. In order to make K-Pop a sustainable growth engine of Korean Wave, the music industry needs to be undertaking various initiatives at a domestic level. The aim of this research is to determine the state of affairs regarding K-Pop revenue model and review possible solutions which will help readers to gain insight into one particular sector of the world economy.
\end{abstract}

Index Terms-Hallyu, korean wave, K-Pop revenue model, music industry.

\section{INTRODUCTION}

Rome was originally the Mediterranean's late bloomer. In contrast to its strong neighbors such as Sparta for military, Carthage for trade, and Greece for philosophy, Rome was inferior. However, Rome had one thing others did not have: openness. Thanks to this trait of assimilation and recreation, Rome could flourish with culture that shaped the world of posterity forever.

Like Rome, South Korea is given a golden opportunity: Korean Wave (Revised Romanization: Hallyu). Hallyu is more than a mere cultural phenomenon; it has a considerable impact on the Korean economy. For instance, Hallyu's inducement coefficient is estimated to be worth around USD $\$ 9.6$ billion dollars in 2012 to over $\$ 50$ billion dollars in 2020. This is even greater than those of G20 Seoul Summit ( $\$ 18.7$ bil), PyeongChang Olympic Winter Games ( $\$ 17.8$ bil), and Yeosu EXPO (\$10.6 bil) combined. [1] K-Pop has played a key role in Hallyu's continuing success. In 2005, K-Pop was ranked as the 33rd music market in the world. Now in 2012, it ranks as the 11th largest market. [2]

Nevertheless, there are factors which foment disturbances and may hinder Korean Wave from sustaining its success. One issue that has come to the forefront is K-Pop's revenue model. The domestic conflict between music producers and service providers is a question that needs to be pondered. Further some suggestions to improve the current revenue system and the reasons why they are practical or not are to be examined, as this will determine the growth prospects of K-Pop and, by extension, the Korean Wave.

Manuscript received July 20, 2012; revised August 20, 20120.

S. Y. Kim is with English Department, Hankuk Academy of Foreign Studies (email: sababi0314@gmail.com).

\section{Problem Focus}

In a capitalistic market, proper valuation is necessary in order for artists to pursue creative works. Basically, they need money to do their job. However, Korean recording industry's current situation can be described as "One sows and another reaps." Income is not distributed evenly which may hamper the industry from flourishing. So this paper focuses on the following areas of subject: study of internal problem within Korean music industry's income distribution and analysis of solutions proposed to refine K-Pop further.

\section{OBJeCtIVES}

Objectives of the study: This study has the following objectives:

1) To identify problems underlying K-Pop revenue model which may potentially threaten the sustainable success of Korean Wave

2) To go over several suggested solutions critically in order to find ways for improvement

\section{REVIEW OF LITERATURE}

According to Maeil Business Newspaper Hallyu's True Colors Project Team, music makers of Korea, including artists, producers, lyricists, and composers, cannot make more than half of the profits by digital music market's standard; they generally take $36 \%$ of the total profit. This directly contrasts with Apple's iTunes, in which creators take $70 \%$ of the profit. Moreover, price of digital music files is set too low. In early 2000, the notion that "buying digital contents is foolish" was rampant among Korean buyers because they could easily download free digital files from the Internet. Unlike the U.S. government which swiftly took legal action against illegal downloading, Korean government took slow and passive action. Consequently, the nominal price of a song is $\$ 600$ (\$0.52). However, considering the purchasing system and discounts offered, the effective price is $30 \sim 50$ (\$0.03 0.04). So these facts directly show that Korea's cultural market is not stabilized yet. [1]

An analysis of 'K-Pop Hallyu Index', which gauges new Korean Wave's popularity, shows that K-Pop reached its apex after it started to expand overseas for 10 years. SERI (Samsung Electronics Research Institute) calculated this index by combining K-Pop's amount of export and market breadth (domestic popularity), Korea's international balance of payments for audiovisual service (international popularity), and Google's 'Search Volume Index' (online popularity). [3]

K-Pop's success is attributed to entertainment 
management companies' systemized production of stars that is comprised of four steps. The steps are: 1. After thorough research, companies cast potential stars; 2 . For a prolonged term, potential stars are trained to be best entertainers; 3 . Works are produced by maximizing its global source of resources; 4. Utilizing local partners, stars are promoted globally. [3]

The most urgent task is to improve K-Pop's complex revenue system. In Korea, music distribution companies hold a very large portion of the total revenue. The services they provide maximize service companies' profits while minimizing copyright holders' profits. Unless institutional reform is undertaken, music producers' rights will continue to be infringed upon. [4]

\section{RESEARCH Methodology}

To examine the question of identifying problems of current K-Pop revenue model, it would do well to investigate an economic white paper provided by Korean Ministry of Culture, Sports, and Tourism. The collected data were divided into two groups (overseas and domestic) in order to contrast them and point out how severely complex and unfairly distributed the K-Pop music market is.

Prior to that, in order to show the trend of K-Pop's success over the past few years, a strong and up-to-date public opinion poll service called 'Google Trends' was used. Google Trends is a public web facility of Google Inc. that shows how often a particular search-term is entered relative to the total search-volume across various regions of the world [5] The data is based on Google Search, the most-used search engine on the Internet, receiving several hundred million queries each day, and thus reliable. Search words 'K-Pop' and 'J-Pop' were typed in together, showing phases for the past years.

Lastly, an inter-industry relation table was drawn in order to analyze the relationship between K-Pop and other industries. These industries were divided into forward production and backward production, according to respective effects.

\section{DATA ANALYSIS}

\section{A. Analysis of Popularity}

When the data were analyzed, it showed that as of yet, K-Pop's popularity has not blown over. As the method of data analysis, a reliable source called 'Google Trends' was used.

Google Trends' advantage is that it shows the flow of public's interests in real time. That is, in the case of consumer goods and services, one can find out what product and service is 'hot' without conducting a separate poll. This can be a useful tool in society where application of information is becoming faster than ever. In the past, investors had to wait 45 days after the end of a quarter in order to check out respective company's quarter results. When they tried to predict the result, they had to rely on company guidance, industry news, or sales statistics, which all lacked accuracy and were time-consuming.
Google Trends can be especially useful under two conditions: 1 . When a company produces consumer goods or is in a service industry; 2 . When a company focuses on major products rather than using multiple-product pricing, or has a clear brand name. In case of K-Pop, it refers to the former, as $\mathrm{K}$-Pop industry is one sector of the Korean Wave operating as a service industry.

So Google Trends was an apt tool to analyze people's interests toward K-Pop. In fact, it was difficult to figure out how popular K-Pop by solely relying on mass media. Using Google Trends allowed finding out the trend of world consumers.

Several search terms were selected. Using commas to compare multiple search terms, K-Pop (Korean music) and J-Pop (Japanese music) were typed in. The following is the figure of trends comparing K-Pop and J-Pop.

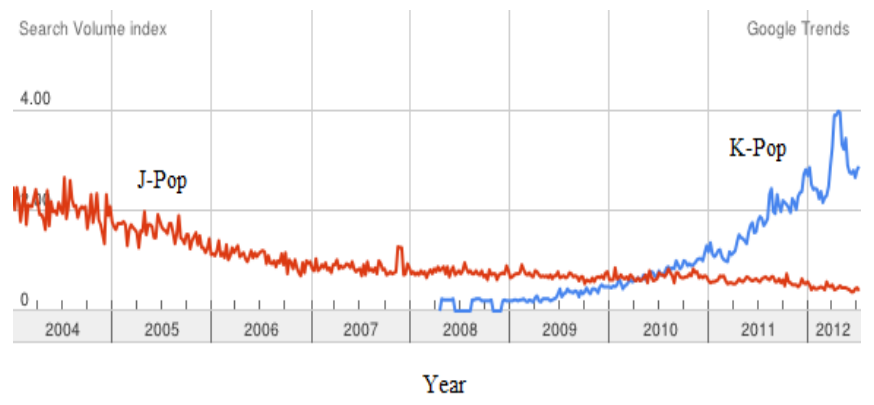

Fig. 1. A comparison between K-Pop and J-Pop using google trends

In Fig. 1, it is shown that J-Pop's popularity has been steadily decreasing since 2004 . In contrast, the global volume of the keyword 'K-Pop' has been increasing exponentially since 2008. The trend is still continuing to increase these days. The popularity of K-Pop could be accurately verified by objective statistical data.

Analysis of relatively scaled search volume index revealed that J-Pop's index has dropped from 4.45 in January 4, 2004 to 0.75 in July 8,2012 . This is rather a gradual decrease over a long span of years. K-Pop's relative index has increased in quite a short period of time. In April 27, 2008, the index recorded 0.45 . It rapidly increased, reaching its apex of 7.65 in April 29, 2012. In the near future, this trend is likely to continue.

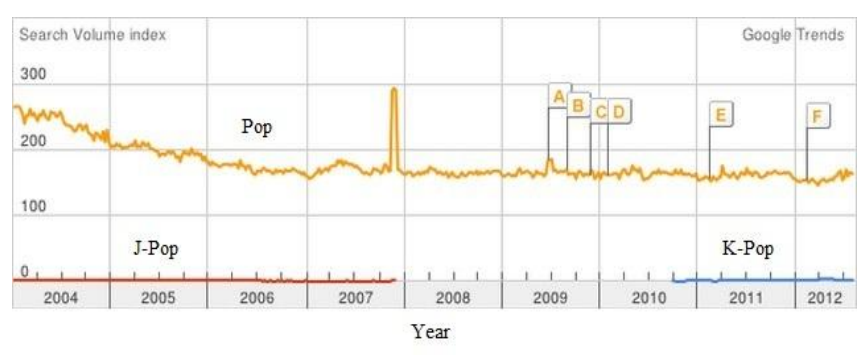

Fig. 2. A comparison of K-Pop, J-Pop, and pop using google trends

However, Fig. 2 shows another aspect of this popularity. If $\mathrm{K}$-Pop is viewed from a larger scale along with a more established entertainment industry like Pop (American music), it can be found that K-Pop's popularity is yet insignificant. This suggests that it is still early to conclude that K-Pop is currently reaching the apex of its popularity. 


\section{B. Analysis of Profit Distribution}

Since there are so many commonalities between K-Pop and J-Pop's success factors, there is a high chance that K-Pop will repeat J-Pop's failure. Clear indication of flaws and sequentially reforms are needed.

The aforementioned literature review of [4] puts emphasis on institutional reform of K-Pop's revenue model. Internally there is a major problem underlying the system; it is too complex and unfair for the real makers of music. Great proportion of advantages and profits are taken by the distribution company, a convoluted organization of such an industry.

TABLE I: PROFIT DISTRIBUTION OF OVERSEAS AND KOREAN MUSIC INDUSTRY

\begin{tabular}{|c|c|c|c|c|c|c|c|c|c|c|c|c|c|c|}
\hline \multirow[b]{2}{*}{ Region.; } & \multirow{2}{*}{\multicolumn{2}{|c|}{ Service. }} & \multirow[b]{2}{*}{$\begin{array}{l}\text { Price (excluding } \\
\text { VAT). }\end{array}$} & \multicolumn{8}{|c|}{ Profit of Music Makers. } & \multirow{2}{*}{$\begin{array}{c}\text { Online } \\
\text { Service } \\
\text { Provider. }\end{array}$} & \multirow[b]{2}{*}{$\%}$. & \multirow{2}{*}{$\begin{array}{c}\text { Profit of } \\
\text { Music } \\
\text { Maker } \\
\text { per song. }\end{array}$} \\
\hline & & & & Subtotal.. & $\%$ & $\begin{array}{l}\text { Composer \& } \\
\text { Lyricist. }\end{array}$ & $\%$ & Performer., & $\%$. & Producer. & $\%$ & & & \\
\hline Overseas.r & \multicolumn{2}{|c|}{ Price per song (झ). } & 1099/song.: & 769.1 & 70.0. & 110. & 10.0. & $\therefore$ & $\because$ & 659. & 60.0. & 330.1 & 30.0. & 769. \\
\hline \multirow{5}{*}{ Domestic. } & \multirow{4}{*}{ Cable. } & Download/song. & 600/song.: & 324. & 54.0. & 54. & 9.0 .1 & 30. & 5.0 .1 & 240. & 40.0 .1 & 276. & 46.0. & 324. \\
\hline & & $\begin{array}{l}\text { Meter-rate system } \\
(40 \text { songs }) .\end{array}$ & $\begin{array}{l}5000 / \text { month . } \\
(125 / \text { song). }\end{array}$ & 2635 & 52.7. & 410. & 8.2. & 235, & 4.5. & 2000. & 40.0 & 2365. & 47.3. & 66. \\
\hline & & $\begin{array}{l}\text { Meter-rate system } \\
(150 \text { songs }) .\end{array}$ & $\begin{array}{l}9000 \text { month. } \\
\text { (60/song). }\end{array}$ & 5400. & 60.0 & 900. & 10.0 & 450. & 5.0. & 4050. & 45.0 .1 & 3600 & 40.0 & 36. \\
\hline & & $\begin{array}{l}\text { Flat-sum system } \\
\text { (DRM). }\end{array}$ & 10000 month. & 4800 & 48.0. & 800. & 8.0. & 400. & 4.0. & 3600 . & 36.0 & 5200. & 52.0 & $\therefore$ \\
\hline & Wireless.r. & Ringtone. & 800 /song., & 308, & 38.5. & 72. & 9.0 .1 & 36. & 4.5. & 200. & 25.0 .1 & 494. & 61.5. & 308.1 \\
\hline
\end{tabular}

After analysis of the economic white paper, a table was created in order to put in necessary information and contrast foreign and domestic market at the same time in one place. The following table shows the profit distribution of Korean music industry.

The table was arranged according to the following format: 1. Region was divided into two sections: overseas and domestic markets. This enabled the comparison of two distinct markets, 2 . For service section, overseas had only one major policy of setting a definite price of a song. Korea's music market had to be specified into various services, proving that the market is in a complex state, 3. Profit earned and respective proportion out of the total by music makers and distributors were specified, showing how relatively unfair treatments toward the Korean music creators are despite their effort.

In case of overseas market, the price of a song is set at \#1,099 (\$0.99). Music makers earn 70\% of the total profit, noting that the rights of music makers are relatively high. Not only in the United States, but also in other Western countries, this policy is widely used.

Comparison between the two different revenue systems emphasizes some problems of K-Pop's system. First of all, the service could be divided into two categories: cable and wireless service. In cable service, one notable service is flat-sum system. If music buyers pay a fixed amount of money per month, they are able to listen and buy music for as often as they want. Flat-sum system is the most widely used type of service in South Korea. While other services are not relatively influential, flat-sum system takes up a high proportion of usage. In the table, music makers hold $48 \%$ of total profit, a significantly low value. Meter-rate system, a policy of paying for the service based on the amount of consumption of the service, has a high percentage of $60 \%$. However, since this system was only recently introduced to South Korea, its effect will be meager.

Moreover, the profit derived from ringtones in wireless service is even lower, indicating $38.5 \%$. This suggests that in contrast to overseas music industry, the Korean environment provides no fair financial chance to the music makers. Wireless service is expected to increase gradually since smartphone users are increasing day by day. Currently in
Korea, $51.4 \%$ of 52,550,000 Koreans are using smartphones. Wireless service is becoming more essential to the music industry.

In fact, many online music distributors maximize their profits while minimizing music makers' gains. Their change of service lures many customers because superficially the services provided are cheaper. Customers do not know the real situation regarding the market structure, thereby choosing flat-sum system which is eventually harmful to the music makers.

\section{A. Analysis of Relationship between K-Pop and Other Industries}

Because of its defects, K-Pop has much room for improvement. One of the opportunities is K-Pop's multiple roles in developing other industries.

In order to find out about the relationship between K-Pop and businesses, several factors were analyzed. Respective industry's investment input and output were calculated into production inducement coefficient. As a result, K-Pop's relation to other industries were listed from high to low in the following order: drama, movie (broadcasting), advertisement, distribution (wholesale-retail), restaurant, fashion (clothes and ornaments), and cosmetics. Then an inter-industry relation table was made.

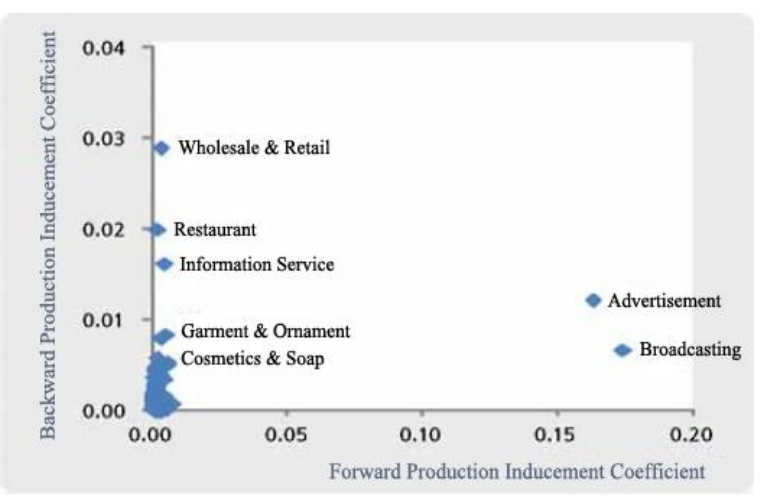

Fig. 3. Inter-industry relation table of K-Pop and other industries

The $\mathrm{x}$-axis of the graph is forward production inducement coefficient, an index measuring the degree of production 
prompted by intermediary goods. In this case, K-Pop is used as intermediary good to invigorate broadcasting and advertisement industry. The $y$-axis of the graph is backward production inducement coefficient that measures the degree of effect induced by K-Pop indirectly. Other businesses such as wholesale-retail, restaurant, information service, clothes, ornaments, and cosmetics are greatly affected by K-Pop's success.

This graph suggests that K-Pop can continue its success through production of derivatives. Since other industries are highly related, there is a greater chance to create added value to what already exists.

These days some Korean companies are already utilizing K-Pop's such potential. In July $27^{\text {th }}, 2012$, KT Music, a subsidiary company of South Korea's Korea Telecom (KT), and Nexon, a South Korean developer of video games, established a strategic partnership. Now Nexon members can easily use music services provided by KT Music and share music through Nexon's SNS (Social Network Service). This groundbreaking arrangement suggests that convergence of K-Pop and game contents industries can create a synergy effect. [7]

\section{CONClusion}

The analysis revealed some useful facts, which could be the basis for drawing inferences and suggest methods to improve the business of K-Pop and its revenue system. Firstly, analysis of popularity provided objective data proving how popular K-Pop is. The Google Trends' figure suggested how fast K-Pop has developed in such a short period of time, contrasting with J-Pop. However, the pattern implies that K-Pop may follow J-Pop's path as well. For instance, lack of motivation due to the unfair revenue system may hinder creativity of artists. As a result, less original music will be produced. And as listeners of J-Pop did, they can become bored with K-Pop in the near future. It has become evident that speculation of existing problems and suggestion of solutions were necessary.

It is also noticeable from the analysis of profit distribution that the internal problem is a surprisingly severe one. Significant difference between the overseas market and the domestic market in the distribution of profit showed the need for reform. The rights of music makers are especially infringed upon, possibly hindering them from creating future artwork they want. Curbed creativity and motivation will harm K-Pop's overall quality as well, eventually reaching the demise of the new trend.

Lastly, the analysis of the relationship between K-Pop and other industries emphasized K-Pop's important role in contributing to numerous businesses. One notable feature was the inter-industry relation table, which was useful to estimate any possibility of extending K-Pop's success. Some researchers regard this state as the preparation for another Korean Wave, calling them K-Culture altogether. The case of cooperation between KT music and Nexon suggests a need to seek for win-win strategy which may help K-Pop sustain its success. As the driving force of Hallyu, K-Pop needs to stay at a healthy condition.

\section{REFERENCES}

[1] Maeil Business Newspaper Hallyu's True Colors Project Team. Hallyu's True Colors: Over Asia To World, Culture Power Korea Project, Seoul: Maeil Business Newspaper, 2012. Print.

[2] IFPI (International Federation of the Phonographic Industry). Digital Music Report 2012. Rep. pp. 22, Jan 2012. Print.

[3] M. S. Seo , D. H. Lee, S. Y. Hong, and T. S. Jeong. K-Pop's Success Factors and Application Strategy of Corporation. Rep. no. 841.: SERI (Samsung Electronics Research Institute), 2012. Print. CEO Information.

[4] Republic of Korea. Cong. Senate, 2011 Hallyu's Trend and Direction of Development - Music. By Won Jae Heo. S. Rept. Busan: Parliamentary Inspection of the Administration Policies Sourcebook, 2011. Print.

[5] About Google Trends. N.p., n.d. Web. (18 July 2012). [Online]. Available: http://www.google.com/intl/en/trends/about.html.

[6] Exchange rate was based on that of July $16^{\text {th }}, 2012.17: 54$. Notification No.063 by Korea Exchange Bank. $\$ 1.00=11,147.00$

[7] M. R. Roh. KT Music, Partnership with Nexon..Music+Game Contents Grafting. Asia Economics. N.p., 27 July 2012. Web. (15 Aug). 2012 [Online].

Available: http://www.asiae.co.kr/news/view.htm?idxno=201207271054436742

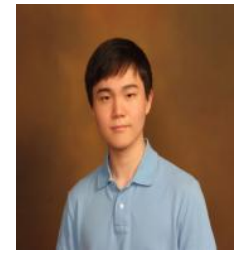

Sang Yeob Kim first author, was born in Gwangju Metropolitan City, South Korea on March $14^{\text {th }}, 1994$ $\mathrm{He}$ is currently a senior at Haknkuk Academy of Foreign Studies, a private boarding school located in the northern part of Yongin, South Korea. Kim majors in English and his major fields of study are economics, history, and music.

In summer of 2010 he worked for Ethan \& Alice Marketing and conducted a research about CSR (Corporate Socia Responsibility) of Korean firms. In winter of 2010 he was an intern at Yuji Partners and studied South Korean financial institutions' roles, vessel fund U.S. government real estate fund, and world financial leaders. In summer of 2011 he completed the role of intern for Camp Korea at Korea University, South Korea as an assistant English teacher. In summer of 2012, he worked as a research intern at Yonsei School of Business and conducted a research about Korean Wave and its relevant businesses.

In May of 2012, Mr. Kim was accepted to IJAS (International Journal of Arts and Sciences) held at Ryerson University, Toronto, Canada, with a thesis titled The History of Sicilian Mafia from an Economic Perspective. 